\title{
Desktop Hachure Maps from Digital Elevation Models
}

\author{
Patrick J. Kennelly \\ GIS Manager \\ Montana Tech of the University of Montana \\ Montana Bureau of Mines and Geology \\ 1300 W. Park St. \\ Butte, MT 59701 \\ Phone: (406) 496-2986 \\ Fax: (406) 496-4451 \\ E-mail: pkennelly@mtech.edu
}

\author{
A. Jon Kimerling \\ Professor \\ Oregon State University \\ Department of Geosciences \\ Corvallis, OR 97331 \\ Phone: (541) 737-1225 \\ Fax: (541) 737-1200 \\ E-mail: kimerlia@geo.orst.edu
}




\section{Introduction}

A classic cartographic technique for representing three-dimensional topography on a twodimensional map involves the use of hachures. A fine line or hachure is generally drawn in the direction of steepest topographic gradient. Hachuring across an area creates tonal variations throughout the map. These tonal variations are a form of analytical hillshading, creating a three-dimensional representation of the topography. Such hillshading can employ vertical or oblique lighting techniques to create such effects.

Hachures display quantitative measures of the topography's slope and aspect. The slope is the angle from horizontal of the steepest topographic gradient, while the aspect is the azimuthal angle from north measured in the clockwise direction. Because hachures are quantitative representations of these components of topography, rules have been established for the construction of such graphics. The general rules vary depending on whether the hachure is part of a large-scale or small-scale map, and whether a theoretical vertical or oblique lighting is used to illuminate the hachures.

\section{Large-scale hachure maps with vertical illumination effect}

Major J.G. Lehmann in 1799 was the first to systematically represent the terrain with hachures. He used lines oriented in the aspect direction with the thickness of the line proportional to the slope. The resulting maps proved especially useful for construction of large-scale topographic military maps (Robinson et. al., 1995). Increasing the hachure 
thickness with slope was named "slope hachuring" and can be equated to analytical hillshading with vertical illumination.

Imhof (1982) outlined five rules for the creation of slope hachures for large-scale maps:

1)Hachures follow the direction of steepest gradient

2)Hachures are arranged in horizontal rows

3)Hachure length corresponds to the local horizontal distance between assumed contours of a certain interval

4)Hachure width is thicker for steeper slopes

5)Hachure density remains constant throughout the map area.

All of the above rules should be obeyed to construct large-scale hachure maps with vertical illumination. To create hachures with the appearance of oblique illumination, rule five is modified. To create hachures for a small-scale map, defined by Imhof (1982) as smaller than 1:500,000, more rules are relaxed to allow what Imhof calls a freer graphic portrayal.

\section{Large-scale hachure maps with oblique illumination}

Oblique illumination of hachures produces "shadow hachures." Varying the thickness of hachures on illuminated versus shadowed slopes creates modulations in tone associated with oblique illumination. Hachures on illuminated slopes are thinned to create this effect. This violates Imhof's fifth rule, but gives a strong impression of the third 
dimension, especially in mountainous areas. The 'Dufour' maps of the mid-1800's are particularly striking cartographic representations of mountainous large-scale topography

(Figure 1). One drawback of shadowed hachure maps, as Imhof (1982) points out, is that thinner shadow hachures on illuminated slopes can be misinterpreted as flatter topography.

Yoeli (1985) developed computer algorithms that would allow the user to create largescale hachures from digital elevation data. This system obeys Imhof's rules, and can be used to create slope or shadow hachures. The construction of hachures with Yoeli's aglorithms is based on digital contours, with beginning points of hachures selected at a given horizontal interval along contour lines. The resulting hachure maps do an excellent job of portraying topographic features on large-scale maps.

Unlike Yoeli, our methodology is designed to produce small-scale hachures. In relaxing some of Imhof's rules we were able to arrive at a simple procedure. Yoeli, in obeying all of Imhof's rules to create large-scale hachures, was required by the nature of the problem to create a much more complex design processes.

\section{Small-scale hachure maps with oblique illumination}

Small-scale hachure maps do not readily comply with the five rules outlined by Imhof (1982). Unlike large-scale hachure maps, which are derived based on the contour's 
structural elements, small-scale maps appear more free-form. Most of these small-scale hachure maps are obliquely illuminated.

In this paper, we outline a methodology for creating small-scale hachure maps with oblique illumination directly from a Digital Elevation Model (DEM). As with most small-scale hachure maps, we violate Imhof's rules 2 and 3, but obey all other rules. We use a grey background with black and white hachures to render oblique illumination while obeying Imhof's rule 4. This tonal method is similar to that used by Tanaka (1950) in creating an obliquely illuminated contour map of a portion of Kyushu, Japan. We refer to the map resulting from our method as an illuminated hachure map.

\section{Location, Data Source, and Software}

We have created an illuminated hachure map that covers a portion of the Cascade Mountains of western Washington state. This area includes the volcanoes of Mt Adams, Mt. St. Helens and Mt. Rainier. This landscape lends itself to hachure mapping with its frequent variations in slope and aspect.

The source data for this map are a 3-arc second Digital Elevation Model (DEM) from the United States Geological Survey (USGS). The DEM is a square grid with cells measuring $92 \mathrm{~m}$. The DEM was derived from an elevation model produced by the Defense Mapping Agency from source data at a 1:250,000 scale. 
We used ESRI's ArcView Version 3.2 for Windows software to create our illuminated hachure map from this DEM. Because it was necessary for us to manipulate grids, we also used the ArcView Spatial Analyst Version 2.0 for Windows extension. In this paper, we outline all ArcView operations and list equivalent commands for ESRI's ARC/INFO Version 7.2 software with the GRID module. Other Geographic Information System (GIS) software that can manipulate and display grids and spatially referenced points should be adaptable to our methodology.

\section{Methodology}

To produce a small-scale obliquely illuminated hachure map, we created a point theme from the DEM that contains both slope and aspect data. We oriented the hachures using the aspect data. Next, we created oblique illumination with both slope and aspect data. We used aspect data to divide point data into illuminated and non-illuminated hachures. In addition, we used the slope data to vary the thickness of individual hachures. We present a step-by-step guide to our methodology below.

The first step was to aggregate grid cells of the 92 meter DEM to create a 277 meter DEM using a mean value of the nine contributing grid cells. This aggregation was necessary to create an attractive and legible hachure map at our selected scale. We aggregated the grid by cutting and pasting a short script in ArcView Help (under Aggregate, then Example). In the ARC/INFO GRID module, use the Aggregate command. 
In order to make illuminated hachures, it is necessary to have both slope and aspect information. We calculated slope and aspect grids for the aggregated DEM using the Derive Slope and Derive Aspect items under the Surface dropdown menu. We converted these floating point grids to integer grids, a step necessary before they can be converted to point themes. To do this, we used the Map Calculator under the Analysis menu. The calculation dialogue box prompts for a grid theme (slope or aspect), and then an operation to apply to this theme. In this example, we used the arithmetic Integer operation, which truncates the floating point aspect or slope number. In the ARC/INFO GRID module, use commands Slope, Aspect and Int to perform the same operations.

Next, we converted slope and aspect grids into point themes. We used a sample ArcScript from the ESRI website (www.esri.com). The Raster to Vector Conversion script, written in Avenue by Kenneth McVay, converts a grid to a point theme. We gave unique attribute field names to slope and grid values in the point themes. In ARC/INFO, use the command Gridpoint to convert a grid to a point coverage.

We joined the slope and aspect themes in ArcView based on location. To perform a spatial join, the table of one theme is the source, the other is the destination. We select the Shape field in both tables. We use the Join button or the Join option under the Table dropdown menu to combine attributes into a single table. The resulting spatial join for two point themes will write all attributes from the source table to the nearest point in the destination table, making all slope and aspect information available in one theme. No 
command exists in ARC/INFO to perform a spatial join, but the same result could be achieved through a series of commands or a script. One option would be to Buffer one point coverage, then Intersect it with the other.

We used aspect values to orient hachures in the direction of steepest slope. The convention for rotating point symbols in ArcView is counterclockwise from north, while the convention for aspect angle is clockwise from north. As such, we multiplied the aspect value by -1 . The modified aspect values define the direction in which hachures are drawn. We specified this variable as the Rotation Field in the Advanced option of the legend editor for the point theme. In ARC/INFO's ArcPlot module, rotate the hachure with the Markerangle command.

We used both aspect and slope values to create the illusion of oblique illumination. We separated points representing hachures in the illuminated and non-illuminated direction into two new themes. We selected an illumination azimuth of $45^{\circ}$. Then we selected all points with aspect values within $90^{\circ}$ of the illumination direction (original aspect range $45^{\circ}$ through $135^{\circ}$ ) and saved these to a new theme. These are the illuminated hachures, which we displayed as white arrows. We saved all other points to a second theme. These are the non-illuminated hachures, which we displayed with black arrows. We made the background gray so that both black and white hachures are visible.

We enhanced the illumination effect by varying arrow thickness with slope. In this example, we chose three classes of slope: the first from $2^{\circ}$ to $4.6^{\circ}$ was drawn with a 6 
point arrow, the second from $4.6^{\circ}$ to $7.2^{\circ}$ with an 8 point arrow, and the third from $7.2^{\circ}$ to the maximum slope, $17.4^{\circ}$ with a 10 point arrow. Because hachures generally do a poor job of representing gently sloping topography, we did not include any hachures with slopes below $2^{\circ}$.

\section{Discussion}

The resulting hachure map is presented at a scale of 1:450,000 in Figure 2. The hachures generally represent the topography in an accurate and easily interpretable manner. Black and white hachures on gray remove ambiguity of slope steepness associated with some shadow hachure maps. The use of arrows further eliminates any confusion that could arise from bi-directional lines in determining azimuth in topographically complex areas.

Our process obeys three of Imhof's five rules of hachuring. Hachures follow the direction of steepest gradient, as in nearly all hachure maps. Hachure width is thicker for steeper slopes, made possible with oblique illumination by using black and white arrows on a gray background. Lastly, hachure density remains constant throughout the map area, except in areas of slope less than $2^{\circ}$. This result follows from using a regular grid as the source data. Although hachures are evenly spaced, the subtle changes in orientation $\left(1^{\circ}\right.$

of aspect) and the small size of the hachure produces a map we believe has the free-form look associated with small-scale hachure maps. 
Figure 3 includes some small areas of hachures within a larger white area with slopes less than $2^{\circ}$. These isolated areas of hachures have often been excluded in hand rendered hachure maps. If it is desirable to eliminate these hachures, the offending points can be selected by location and deleted from the GIS point themes.

Lastly, we stress that the hachure map here is a generalization and does not fully exploit the data in the DEM. One generalization was the aggregation of the DEM from 92 to 277 meters, a step necessary for clarity. Also, an analytical hillshading of the data would show more detail of landscape than this hachure map. One example of this is the Mt St. Helens caldera, discernible with analytical hillshading of the $277 \mathrm{~m} \mathrm{DEM}$. The transition from shaded areas used in hillshading to linear point symbols used in hachuring is a generalization inherent in the hachuring process.

\section{Bibliography}

Imhof, E. 1982. Cartographic Relief Presentation. Berlin and New York: Walter de Gruyter.

Lehmann, J. G. 1799. Darstellung einer nueun Theorie der Bergzeichnung der schiefen Flächen im Grundriss oder der Situationszeichnung der Berge, Leipzig.

Robinson, A.H., J.L. Morrison, P.C. Muehrcke, A.J. Kimerling, and S.C. Guptill. 1995. Elements of Cartography, $6^{\text {th }}$ ed. New York: John Wiley and Sons. 
Tanaka, K. 1950. "The relief contour method of representing topography on maps." Geographical Review 40:444-56.

Yoeli, P. 1985. "Topographic relief depiction by hachures with computer and plotter." Cartographic Journal 22: 111-24. 


\section{Figure Captions}

Figure 1. A portion of a large-scale topographic map using obliquely illuminated hachures to represent topography. (From Sheet 19 [1858], Switzerland, 1;100,000, the "Dufour map.”)

Figure 2. A small-scale hachure map of the Cascade Mountains of Washington state with illumination from the northeast. The scale is $1: 450,000$ and north is to the top of the page. Mt. Rainier is near the north edge and central. Mt Adams is in the southeast corner and Mt. St. Helens is in the southwest corner. The Cowlitz River valley cuts through the central portion of the map. 